\title{
The Importance of Metacognitive Reading Strategy Awareness in Reading Comprehension
}

\author{
Mohammad Reza Ahmadi ${ }^{1}$, Hairul Nizam Ismail ${ }^{1} \&$ Muhammad Kamarul Kabilan Abdullah ${ }^{1}$ \\ ${ }^{1}$ School of Educational Studies, Universiti Sains Malaysia, Malaysia \\ Correspondence: Mohammad Reza Ahmadi, School of Educational Studies, Universiti Sains Malaysia, 11800, \\ Penang, Malaysia. Tel: 60-17-527-1870. E-mail:mr.ahmadi2720@gmail.com
}

Received: June 15, 2013 Accepted: July 6, 2013 Online Published: September 4, 2013

doi:10.5539/elt.v6n10p235 URL: http://dx.doi.org/10.5539/elt.v6n10p235

\begin{abstract}
Metacognitive reading strategy awareness plays a significant role in reading comprehension and educational process. In spite of its importance, metacognitive strategy has long been the ignored skill in English language teaching, research, learning, and assessment. This lack of good metacognitive reading strategy skill is exacerbated by the central role of reading comprehension in education success. One solution to the problem of poor reading comprehension is the learning of metacognitive reading strategy skills. Metacognitive reading strategy ability needs to be focused in language learning and teaching. The present study is an attempt to find out whether "meta-cognitive reading strategy awareness" enhances EFL students' reading comprehension. Furthermore, it attempts to detect the relationship between metacognitive reading strategy awareness and reading comprehension. This paper focuses on the four main issues. First, it discusses the definition of metacognitive reading strategy, the significance of metacognitive reading strategy. Second, it reviews the process of metacognitive reading strategy. Third, definition of reading comprehension and different models of reading comprehension are reviewed. Fourth, the relationship between metacognitive reading strategy and reading comprehension will be discussed. Findings based on the review of the literature along with analysis of the data are of great significance and can be advantageous to improve EFL learners' metacognitive reading comprehension skill. Metacognitive reading comprehension skill has a positive effect on learning a second language and learners can gain the skills they need for effective communication in English.
\end{abstract}

Keywords: metacognitive reading strategy, reading comprehension, EFL students, teaching metacognitive strategy

\section{Introduction}

The improving number of international communication, traveling and studying in abroad, students need to learn four skills of listening, speaking, reading and writing for their success. But reading comprehension is one of the main important elements for their English language learning. Research shows that reading comprehension is a complex process and students usually have difficulties in constructing meaning from writing text (Grabe \& Stoller, 2002). General study suggests that who starts to learn English language is most likely to have serious difficulties in constructing meaning and understanding of the texts. This difficulty has been focused by investigators for a long time and in recent years, they suggested that metacognitive reading strategy is an effective factor that fostering reading comprehension among readers (Salataki \& Akyel, 2002).

Many students of EFL/ESL have "major difficulties" with English reading comprehension even after years of learning the English language. This often results in them facing difficulties in areas such as finding employment or a better job. They can read a text but for recognizing or understanding the authors' message/messages often encounter with difficulties. According to Ahmadi and Hairul (2012), reading comprehension is an important factor in EFL/ESL learning process and should be emphasized in different levels of education, for instance, reveals that an area of concern and indeed one of the top priorities of ESL/EFL students after completing elementary English courses is reading comprehension. Despite this, the teaching of reading comprehension strategy remains largely neglected in the field of English language teaching. In this study, the researchers discuss common misconceptions about reading comprehension, factors affecting the learning of comprehension. Then, they review the needs of learners, suggestions for teaching metacognitive reading strategy. 
Metacognitive reading strategy awareness has become one of the effective ways to facilitate students reading comprehension in the field of second/foreign language studies. Early studies on metacognitive reading strategy awareness tended to make lists of strategies and other features presumed to be necessary for all language learning students (Oxford, 1994). In the previous study, researchers tried to explore what language learners do to facilitate their learning to the processes included in EFL/ESL learning. In this new approach metacognitive reading strategy awareness is defined as any choice, behavior, thought, suggestion and technique used by a reader to help their learning process (Cook, 2001; Macaro, 2001; Oxford, 1990). Then researchers attempted to create taxonomies of metacognitive reading strategy among readers to facilitate their comprehending texts which attracted more attention and still continue to do so (Rubin, 1987; Oxford, 1990; O'Malley \& Chamot, 1990).

Flavell (1981) elaborated meta-cognition as cognition about cognition and mentioned the differences between metacognitive knowledge and metacognitive experience. Flavell reveals that meta-cognition refers to both people's awareness and control, not only of their cognitive processes, but of their desires and motivations as well. Teachers agree that metacognitive reading strategy can be utilized to help student's reading comprehension and promote the monitoring and regulation of one's own cognitive enterprises. The metacognitive strategy implementation such as self-awareness and self evaluating is to improve independent readers who can control their own learning and learn, when and how to use those strategies while reading, Flavell (1981).

\section{Cognitive and Metacognitive Reading Strategies}

Metacognitive reading strategy awareness, are strategies that help students to regulate or monitor cognitive strategies. They are the notions of thinking about thinking, and are defined as, planned, intentional, goal directed, and future-oriented mental processing that can be used to accomplish cognitive tasks (Salataki \& Akyel, 2002; Phakit, 2003). Furthermore, metacognitive strategies differ from cognitive ones in that they span multiple subject areas while cognitive strategies are likely to be encapsulated within a subject area so, readers who are meta-cognitively aware know what to do when they face difficulties in learning, they would utilize strategies for recognizing what they should do. Metacognitive strategies indicate one's thinking and can facilitate more learning and developed performance, especially among students who try extremely hard to understand the written context.

Rmesh (2009) explained that recognizing and monitoring cognitive processes may be one of the most important skills that lecturers, teachers and instructors can assist EFL/ESL students' enhancement. Metacognitive reading strategy awareness skills should be considered and taught as a valuable use of instructional time by second/foreign language instructors. When students reflect upon their learning strategies, they become better prepared to make conscious decisions about what they can do to promote their learning. Therefore, metacognitive reading strategy skills are emphasized in second/foreign language learning classrooms. Similarly, Wang et al, (2009) argued that metacognitive reading strategies have various benefits on students' reading comprehension and fostering their learning activities. Investigation on university EFL students about metacognitive beliefs and strategies for learning in China indicated that metacognitive reading strategies' beliefs, which show learners who are confident about their ability to learn a foreign language, and also metacognitive strategies are positively associated with learners' learning achievement results. As a result in this section, students who have confidence in their learning process and can utilize metacognitive reading strategies such as, planning, monitoring and evaluating are more successful than those students that do not use this strategy in their learning and reading program (Wang, et al, 2009).

Cognitive strategies include direct interaction with the task and help to facilitate comprehension, act directly on incoming information, manipulating it in ways that improve learning. Cognitive strategies can be divided as the following elements: recognizing, using topics, guessing from the context, using a dictionary, writing down, imagery, activating background information, summarizing, using linguistic clues, using text markers, skipping the difficult parts' and repeating words or phrases. In other words, metacognitive reading strategies are higher order performance methods that refer to the planning, monitoring, and evaluating the success of a learning activity (Pressley \& Afflerbach, 1995).

According to Mokharti and Reichard (2002), metacognitive reading strategy awareness is of interest not only for what they indicate about the ways students arrange their interaction with the context, but also for how the use of strategies is related to effective reading comprehension. Metacognitive reading strategy awareness is emphasized in the field of reading comprehension process, which has been indicated as an important factor for reading strategies while reading. Many researchers agreed that there are differences between metacognitive knowledge, which refers to the knowledge of cognitive and metacognitive skill which is defined as regulation of cognition. Accordingly, Veenman, Kok, and Blöte, (2005), Veenman, Van Hout-Wolters, and Afflerbach (2006) stated that 
metacognitive knowledge is defined as one's own declarative knowledge about the interactions between individual characteristics, context and the available strategies. However, many other investigators defined 'metacognitive knowledge' as a synonym for 'metacognitive awareness' (Juliebo, Malicky \& Norman, 1998). On the other hand, metacognitive skills are defined as an individual knowledge for monitoring person's learning process (Veenman, Van Hout-Wolters, \& Afflerbach, 2006).

\section{Different Kinds of Metacognitive Reading Strategies}

There are differences between metacognitive knowledge and metacognitive control processes, the first one refers to what learners know about cognition and the second one refers to how learners use that knowledge to regulate cognition (Brown, 1987; Baker, 1991). Accordingly, Brown (1987) said that knowledge of cognition can be defined as what one's know about his/her own cognition. It usually consist of three various types of metacognitive reading strategy awareness: 1) declarative knowledge, 2) procedural knowledge, and 3) conditional knowledge.

\subsection{Declarative Knowledge}

Declarative known is defined as knowing "about" things. It is the knowledge involves information about individual knowledge as a learner, and about what elements affects one's performance. For instance, research investigating meta-memory or knowledge about memorial processes shows that students have knowledge about the cognitive processes associated with memory. Furthermore, good learners indicate to have more knowledge about their own memory and are more likely than poor learners to use what they do know (Desoete \& Roeyers, 2003).

\subsection{Procedural Knowledge}

According to Veenman (2005), procedural knowledge refers to knowing "how" to do things. It is defined as knowledge about the execution of procedural skills. Individuals with a high degree of procedural knowledge use skills more automatically, are more likely to sequence strategies effectively, and use qualitatively different strategies to solve problems. From an instructional standpoint, a number of studies report that helping younger students increase their procedural knowledge improves their on-line problem solving performance (Veenman, 2005).

\subsection{Conditional Knowledge}

Conditional knowledge refers to knowing when and why to apply different cognitive actions (Desoete \& Roeyers, 2003). It may be thought of as declarative knowledge about the relative utility of cognitive procedures. For instance, in an investigation it was found that college students distinguished among the information-processing demands of ten different types of riding situations. Learners selected various strategies most appropriate for each situation in an effort to better regulate their learning.

Therefore, researchers support the claim that skilled learners possess declarative, procedural, and conditional knowledge about cognition. This knowledge usually improves performance. Many theorists believe that metacognitive knowledge appears earlier and continues to develop at least throughout adolescence (Flavell, 1987). Similarly, Baker (1989) stated that good readers indicated to have more information about their own cognition than poor students and are better able to explain that knowledge.

\section{Metacognitive Reading Strategy Regulatory Skills}

Metacognitive reading strategy regulatory skills have three essential skills and are as follows (Jacobs \& Paris, 1987).

\subsection{Planning}

According to Zare-ee (2008), planning involves the selection of appropriate strategies and the allocation of resources that affect performance. For instance, making predictions before reading, strategy sequencing, and allocating time or attention selectively before beginning a task. Furthermore, planning (also called forethought) is the process of thinking about and organizing the activities required to achieve a desired goal. Planning is a fundamental property of intelligent behavior. This thought process is essential to the creation and refinement of a plan, or integration of it with other plans; that is, it combines forecasting of developments with the preparation of scenarios of how to react to them (Miller, 1985).

\subsection{Monitoring}

Monitoring is a strategy that analysis of information as a project progresses. The purpose of monitoring is to improve the efficiency and effectiveness of a project or organization. It facilitates keeping the work on track, and 
help management know when things are going wrong. If done properly, it is an invaluable tool for better controlling and takes care while reading, and it requires a useful base for evaluation. It enables students to determine whether the resources they have available are sufficient and are being well used, whether the ability they have are sufficient and suitable, and whether they are doing what they planned to do (Slife \& Weaver, 1992). Therefore, monitoring refers to personal conscious awareness of comprehension and text performance. The capability to engage in periodic self-controlling while reading is a good example for monitoring.

\subsection{Evaluation}

Evaluation is defined as appraising the conclusion and regulatory processes of an individual's learning. For example, evaluation involves re-evaluating personal's aims and conclusions. It can also be summative (drawing learnings for a completed project or an organization that is no longer functioning). Evaluation is the comparison of actual project impacts against the agreed strategic plans. It looks at what students set out to do, at what students have accomplished, and how they accomplished it. It can be informative,. Many investigations indicate that metacognitive knowledge and regulatory skills such as planning are related to evaluation and is one of the most important factors that facilitates reading comprehension (Baker, 1989).

So, instructors and educators agree that regulatory competence promotes performance in a number of ways, involving better use of cognitive resources such as attention, better utilize of strategies, and a greater awareness of comprehension breakdowns. Researchers stated (Cross, \& Paris, 1988; Brown \& Palincsar, 1989) that if students know when and how to utilize regulatory skills and use them as one of the instructional program in the classroom activities would positively affect their improvement in their comprehension tests. Regulator process (planning, monitoring, and evaluation) need to be emphasized in the learning process and would motivate learners to control their improvement in reading comprehension (Swanson, 1994).

\section{Reading Comprehension}

Reading comprehension refers to the ability of readers to understand the surface and the hidden meanings of the text using meta-cognitive reading strategies. Reading comprehension is a complex process involving a combination of text and readers. It is widely reasonable that the three key types of reading are as; accuracy (involves phonological and orthographic processing), fluency (includes time), and comprehension (Ahmadi, Hairul, \& Pourhossein, 2012; NICHHD, 2000). Perfetti \& Hogaboam (1975) explained the importance of "the conceptualization of reading as composed of separable components" (p. 461), since it allows the investigators to test the relationship among the various of reading components and the way that they are related. The purpose of reading comprehension is to construct meaning from the contexts (Sweet \& Snow, 2002). Reading comprehension is a complex cognitive ability providing the ability to integrate text information with the background knowledge of the reader and resulting in the explanation of a mental representation (Meneghetti, Carretti, \& De Beni, 2006). So, reading comprehension is an interactive activity between students and contexts (Rumelhart, 1994); in the period of this interaction between students and contexts, students utilize different experiences and knowledge which involve language skills, cognitive information and world knowledge.

Researchers found that readers need to utilize a wide range of strategies while reading a text and especially in reading comprehension (Paris, Wasik, \& Turner, 1991), because in reading comprehension process readers should utilize various of conscious and unconscious strategies to solve their problem in order to construct meaning from written message/messages (Johnston, 1983). Metacognitive reading strategy can be either conscious or unconscious or automatically. Metacognitive reading strategies refers to particular, deliberate, goal-directed mental processes or behavior, which control and modify the reader's attempts to understand texts (Afflerbach, Pearson, \& Paris, 2008).

\section{Reading Comprehension Models}

Reading comprehension has three important models that should be emphasized in the reading comprehension process. These models facilitate reading comprehension and help readers to figure out texts and solve their problems while reading (Eskey, 2005). These three major reading models support first and second language learning cognitive processes. They influence both L1 and L2 reading research and can be distinguished from one another by its focus regarding how meaning is attained from print. For example, the bottom-up model shows that the reading process is supported by each word in the text and a learner decodes each word to understand the meaning. On the other hand, the top-down model indicates that the reading process is supported mostly by a learner's background knowledge and prior experience. The last model of reading comprehension (interactive model) refers to the reading process which is supported by an interaction between the text information and the learner's background knowledge as well as interaction between different types of metacognitive reading strategies (Grabe, 2004; Eskey, 2005). These three models of reading comprehension are discussed in details as 
follows;

\subsection{The Bottom-Up Model}

The bottom-up model focuses on the text, teachers, readers begin reading by understanding the words, the letters and gradually improve toward larger linguistic chunks to sentences, and actually ending in meaning Gough (1972). In this model, the whole reading process is based on the words and learners construct meaning from context by recognizing each word. Individual words are emphasized in this model in isolation and rapid word understanding is important in the bottom-up model (vanDuzer, 1999). This model believes that readers who utilize this process quickly become skilled readers. Moreover, readers who are successful at recognizing the words become proficient readers whose proficiency is improved by their ability to decode (Pressley, 2000). Proficient decoders are able to understand frequent letter chunks, prefixes, suffixes, and the original words quickly. So, this ability can release more memory ability in the brain for reading comprehension. On the other word, poor readers put more attempt into recognizing text which leaves less processing ability in the brain for reading comprehension (Ahmadi \& pourhossein, 2012).

Accordingly, (Pressley, 2000) stated that fast decoding increase reading comprehension. Moreover, the bottom-up has been criticized that, all reading goes through a mechanical pattern in which the reader should translate a piece-by-piece mental information in the passage/passages, with little interference from his/her own background knowledge." (Grabe \& Stoller, 2002, p. 32). Additionally, this process that decodes word-by-word, causes slow and taking a lot of time and effort in reading comprehension because short-term memory is overloaded, and readers forget easily what they have read when reading comes to an end (vanDuzer, 1999). It can be concluded that readers may only remember words separately without integrating them into a cohesive recognizing.

Without a cohesive recognizing, no one won't understand critical thinking. Without critical thinking, students will lack the motivation to read on a regular basis. So, the criticism of this model has been that it does not seem to consider the contribution of a reader's active role and background knowledge to reading comprehension. In other words, the linear nature (letters $\rightarrow$ words $\rightarrow$ sentences) of this reading model limits the scope of the reading process or envision the reading process as a one-way makes it fail to notice the global or top-down processes that take place during reading. Recognition of the limitations within the bottom-up model in explaining the reading process led to the emergence of the top-down reading model (Grabe, 2004; Eskey, 2005).

\subsection{The Top-Down Model}

The top-down model refers to a "notion" driven model where the students' prior information and expectations help them to construct meaning from a reading text, Eskey (2005) explains that the top-down model is based "from brain to text" and focuses on the whole reading process. In this model a learner begins with certain expectations about the reading context derived from his/her prior information and then utilizes his/her word information they possess in decoding vocabulary to confirm and modify previous expectations (Aebersold \& Field, 1997). On the other hand, contexts themselves have no meaning in the top-down reading model but they are readers who construct the meaning of the texts by fitting them into his/her background knowledge. Reading comprehension is a "psycholinguistic predicting game" and students use their prior information to predict meaning. According to Smith (2004), who is also famous in this model, stated that a reader acts a very active function in the process of translating print into meaning by using knowledge of a relevant language, subject matter, and how to read to confirm or reject his/her hypotheses. The top-down model process is also called "text sampling" (Cohen, 1990). It means that, it is not necessary a reader to read all of the vocabulary and sentences in the text or read the context, word by word, but rather selects certain vocabularies and phrases to comprehend the meaning of the text and some key words can help the reader to recognize the text quickly.

According to Ahmadi, Hairul, and Pourhossein (2012), the top-down model emphasizes on reading skills like prediction, and summarizing as well as anticipating from texts. The top-down model affects both L1 and L2 reading instruction in improving the importance of prediction, guessing from the text, and getting the gist of a text's meaning. However, the top-down reading model has been criticized for its problem of over reliance on a reader's background linguistic and conceptual information and ignore the importance of the text. Moreover, the top-down model overlooks the possible difficulties that a reader may have or face with predicting the topic of text if the material is unfamiliar to him/her. This is particularly true for second or foreign language learners. Up to this point, both the bottom-up and the top-down models have been considered inadequate in terms of explaining a sound reading process. For the bottom-up model, it was criticized for its failure to consider the reader's function in the reading process, while the top-down model relies too much on the reader's background linguistic and conceptual knowledge and ignores the importance of the text Thus, the inadequacy of both the 
bottom-up and top-down models in interpreting the reading process has led to the emergence of the interactive reading model (Ahmadi, Hairul, \& Pourhossein, 2012; Eskey, 1986).

\subsection{The Interactive Model}

The interactive model is defined as a combination of the both bottom-up and top-down models and emphasizes the interrelationship between a reader and the text. It is now commonly accepted as the most conclusive picture of the reading process for both L1 and L2 readers (Ahmadi \& Pourhossein, 2012). Furthermore, the interactive model suggests that there is an interaction between the bottom-up and top-down processes and this model indicates that neither bottom-up or top-down models can by themselves describe the whole reading process. Similarly, Rumelhardt (1977) states that "both sensory and nonsensory come together in one place and the reading process is the conclusion of simultaneous joint application of all the knowledge sources" (p. 735).

The interactive reading model refers to the reader that "takes into account the critical contributions of both lower-level processing skill (word identification) and higher-level comprehension and reasoning skills (text interpretation)." So, reading comprehension is the result of meaning construction between the reader and the text, rather than simple transmission of the graphic information to the readers' mind (Grabe, 1991). The purpose of this model stresses that a proficient reader simultaneously synthesizes the information available to him or her from several knowledge sources of either bottom-up or top-down in the period of reading process. Additionally, Stanovich (1980) pointed out that the view of "compensation" into the interactive model by proposing that bottom-up and top-down processes compensate for each other in the reading process. On the other hand, when a learner lacks the appropriate content schemata for a certain text, he or she will rely on the bottom-up processes to compensate for the necessary background information. The opposite could be true when a learner lacks the bottom-up skills necessary to comprehend a text, he or she will resort to high level processes. This phenomena explain for the process that poor readers tend to resort to high level processes more often than skilled readers given that the use of top-down processes seems to compensate for the poor readers' limited ability of bottom-up processes (Eskey, 2005; Stanovich, 1980).

\section{Review of Studies on Metacognitive Reading Strategy Awareness}

According to O'Malley and Chamot (1990), most investigations on metacognitive reading strategy awareness in both L1 and L2 contexts has emphasized on clarifying and categorizing the metacognitive reading strategies that proficient readers employ in comparison to less-proficient readers. In the case of metacognitive reading strategy awareness, research on second language and foreign language reading strategies has largely been utilized by research done in L1 reading contexts with the majority of the participants were primary grades or remedial students (Grabe, 1991). Given the differences in language learners and contexts, it is acceptable to ask the validity of using L1 reading research as a starting point of inquiry into L2 reading strategy use. A major concern is the reasonable question of the extent to which less proficient L1 readers are equivalent to less-proficient L2 readers (Grabe, 1991). In other words, to the influence of a learner's first language and literacy, his/her second language proficiency needs to be taken into consideration. Moreover, one cannot neglect that reading is a cognitively learned process for L1 readers, as it is of course for L2 readers as well. For that reason, L2 based research has relied so much on previous L1 work. There are several reasons that L1 reading strategy studies that are relevant to L2 reading (O’Malley \& Chamot, 1990).

Metacognitive reading strategy awareness is higher order performance element that entails planning for learning, monitoring, clarifying and remediation causes of comprehension failure or evaluating the success of a learning activity; that is, the strategies of 'self-planning', 'self-monitoring', 'self-regulating', 'self-questioning' and 'self-reflecting' (Pressley \& Afflerbach, 1995). Between the two categories of reading strategies there is no difference because of the interchangeability in action (Brown, 1987). Metacognitive reading strategies indicate on cognition and provide planning, monitoring, and evaluating that take place before, during, and after reading (Veenman, Van Hout-Wolters, \& Afflerbach, 2006).

In other words, cognitive strategies are related to integrating new material with background information and learners use to acquire, learn, remember, recognize the material while reading include rehearsal, elaboration, and organizational strategies". Cognitive strategies are important to perform a task, while metacognitive reading strategy awareness is necessary to recognize how the task has been performed (Schraw, 1998), as they include both the awareness and the conscious control of one's leaning. Metacognitive reading strategies are of interest not only for what they indicate about the ways readers arrange their interaction with the text, but also for how the use of strategies is related to effective reading comprehension. One of the most important factors that need to be emphasized while reading is metacognitive reading strategy awareness which facilitate reading comprehension and would foster EFL/ESL learning (Mokharti \& Reichard, 2002). 
Recent researchers stressed in the area of reading comprehension which have been increasing emphasis on the role of metacognitive reading strategy awareness, and has been defined as the perceived use of reading strategies while reading (Flavell, 1979; Pressley, 2000).

\section{Correlation between Metacognitive Reading Strategy Awareness and Reading Comprehension}

As mentioned in the previous sections, there is a positive relationship between metacognitive reading strategies awareness and reading comprehension. Accordingly, Flavell (1976) stated that the theoretical framework that supports this study is metacognitive reading strategy awareness theory (Flavell, 1976), it believes that self-monitoring and regulation is the main important factor in reading comprehension. These strategies not only promote reading comprehension but also motivate readers to read more and understand better the written message/messages. Metacognitive reading strategy awareness in reading comprehension processes relates to the knowledge that we recognize ourselves as readers, the reading assignment that we encounter, and the reading strategies that we utilize so as to solve the tasks (Baker \& Brown, 1984; Singhal, 2001). In general, metacognitive reading strategy awareness in reading is defined as the reader-performed actions such as planning, monitoring, or evaluating the success of a particular learning task (O'Malley \& Chamot, 1994).

Metacognitive reading strategy awareness includes the awareness of whether or not comprehension is happening, and the conscious willing of one or more strategies to monitor the reading comprehension. Koda (2005) elaborated that several investigations (Cohen, 2003; Tang \& Moore, 1992) indicated that metacognitive reading strategy awareness has a strong correlation with reading comprehension. In fact, proficient readers utilize various metacognitive reading strategies while reading. In contrast, less proficient or poor readers do not use these strategies while reading so, they cannot improve in their reading comprehension. For instance, Devine (1983) and Shinghal (2001) investigated on second language students' conceptualizations of their second language reading processes through interviews. The results explored that proficient readers emphasize on reading as a meaning-making process rather than a decoding process. Meanwhile, the less proficient readers indicated to do the opposite.

Additionally, Barnett (1988) conducted a study of second language reading with French language students, and the result showed that the proficient readers indicated more awareness of their use of metacognitive reading strategies in reading comprehension than less proficient readers. Furthermore, (Chern, 1993) also explored that there is a positive relationship between readers' metacognitive reading strategy awareness and their reading comprehension process in EFL/ESL learners. Sheorey and Mokhtari (2001) explained that the correlation between learners' reading comprehension ability and metacognitive reading strategy is vital and important for reading procedure. And also in a study in U.S. college student groups, skilled readers indicated a higher level of awareness and strategy use than poor-ability readers. However, recent research comparing the effectiveness of cognitive and metacognitive reading strategy training reveals that explicit teaching of cognitive strategies yields small, short-term developments in reading performance, whereas training on metacognitive strategy results in more stable, long-term comprehension gains (Cohen, 2003; Koda, 2005; Tang \& Moore, 1992; Zhicheng, 1992).

\section{Conclusion}

Reading comprehension can be one of the most important parts for a language learner to master and one of the least favorite topics for teachers to address in the classroom. But most of the students have difficulty with constructing meaning from the written texts. So, as researchers conducted studies in the field of metacognitive reading strategy awareness, they found that metacognitive reading strategy is one of the main important factors to facilitate students' reading comprehension. It can be concluded that universities and schools need to be actively improve metacognitive reading strategies among all students. Research indicates that metacognitive reading strategy awareness promotes both performance and understanding of one's reading comprehension. Research further supports the claim that metacognitive strategies facilitate students' reading comprehension.

This study corroborates the view that explicit instruction of metacognitive reading strategies is a feasible tool to enhance students' reading comprehension and benefited most from explicit reading instruction supplemented by practice in metacognitive reading strategy activities. However, it may be challenging for instructors to practice metacognitive strategy in the conventional way, it is worthwhile because this form of metacognitive strategy was the most effective. Above all, it is important to say that after a relatively short time of reading comprehension instruction, students become self-regulated readers and they can be a proficient reader after finishing this strategy instruction learning. So, then they know when and how to utilize strategy while reading. The general results of this study can be summarized as:

1) Less proficient readers do not use metacognitive reading strategies but proficient readers utilize metacognitive reading strategy while reading texts. 
2) Readers who use metacognitive reading strategy in their reading comprehension are more successful than other readers who do not utilize this strategy in reading comprehension process.

3) In both good and poor readers, there is a positive significant correlation between the use of cognitive and metacognitive strategies; in other words, the more cognitive strategies, the more metacognitive and vice versa.

4) No matter good or poor readers, all the readers take care of skimming and scanning strategies, which are included in the comprehension sub-skills of cognitive strategies but good readers think more deeply to recognize and comprehend the texts adequately ( using metacognitive strategies).

\section{Acknowledgements}

The researchers would like to thank Mr Abbas Pourhossein Gilakjani and Mrs Sareh Shaker Haghighi for their extensive and insightful discussions.

\section{References}

Aebersold, J. A., \& Field, M. L. (1997). From reader to reading teacher: Issues and strategies for second language classrooms. Cambridge: Cambridge University Press.

Afflerbach, P., Pearson, P. D., \& Paris, S. G. (2008). Clarifying differences between reading skills and reading strategies. The Reading Teacher, 61, 364-373.

Ahmadi, M. R., \& Hairul, N. I. (2012). Reciprocal teaching as an important factor of improving reading comprehension. Journal of studies in education, 2(4), 153-173.

Ahmadi, M. R., \& Pourhossein, A. G. (2012). Reciprocal teaching strategies and Their Impacts on English Reading Comprehension. Theory and Practice in language studies, 2(10), 2053-2060.

Ahmadi, M. R., Hairul, N. I., \& Pourhossein, A. G. (2012). Impacts of learning reading strategy on students' reading comprehension proficiency. The International Journal of Language Learning and Applied Linguistics World, 1(1), 78-95.

Baker, L. (1989). Metacognition, comprehension monitoring, and the adult reader. Educ. Psychol. Rev, 1, 3-38.

Baker, L. (1991). Metacognition, reading, and science education. In Santa, C., \& Alvermann, D. (Eds.), Science Learning: Processes and Applications. International Reading Association, Newark, Delaware.

Barnett, M. A. (1988). Reading through context: How real and perceived strategies use affects L2 comprehension. Modern Language Journal, 72, 150-162.

Brown, A. (1987). Metacognition, executive control, self-regulation, and other more mysterious mechanisms. In Weinert, F., \& Kluwe, R. (Eds.), Metacognition, Motivation, and Understanding (pp. 65-116). Erlbaum, Hillsdale, NJ.

Brown, A. L., \& Palincsar, A. S. (1989). Guided, cooperative learning and individual knowledge acquisition. In Resnick, L. B. (Ed.), Knowing and Learning: Essays in Honor of Robert Glaser (pp. 393-451). Erlbaum, Hillsdale, NJ.

Chern, C. L. (1993). Chinese students' word-solving strategies in reading in English. In T. Huckin, M. Haynes, \& C. Coady (Eds.), Second language reading and vocabulary learning (pp. 67-85). Norwood, NJ: Ablex.

Cohen, A. D. (1990). Strategies in second language learning: Insight from research. In R. Phillipson, E. Kellerman, L. Selinker, M. S. Smith, \& M. Swain (Eds.), Foreign/Second Language Pedagogy Research. Cleve: Multilingual matters.

Cohen, A. D. (2003). The learner's side of foreign language learning: Where do style, strategies, and tasks meet? International Review of Applied Linguistics, 41, 279-291.

Cook, V. (2001). Second language learning and language teaching. London: Edward Arnold.

Cross, D. R., \& Paris, S. G. (1988). Developmental and instructional analyses of children's metacognition and reading comprehension. J. Educ. Psychol., 80, 131-142.

Desoete, A., \& Roeyers, H. (2003). Can off-line metacognition enhance mathematical problem solving? Journal of Educational Psychology, 95, 188-200.

Devine, J. (1993). The role of metacognition in second language reading and writing. In G. Joan, \& L. I. Carson (Eds.), Reading in the composition classroom, second languageperspective (pp. 105-130). Boston: Heinle and Heinle Publishers.

Eskey, D. E. (2005). Reading in a second language. In E. Hinkel (Ed.), Book on Second Language Learning and 
Teaching (pp. 563-579). Mahwah, NJ: Erlbaum.

Eskey, D. (1986). Theoretical foundations. In Dubin, F., Esdey, D., \& Grabe, W. (Eds.), Interactive approaches to second language reading. New York: Cambridge University Press.

Flavell, J. H. (1976). Metacognitive aspects of problem solving. In L. B. Resnick (Ed.), The nature of intelligence (pp. 231-236). Hillsdale, NJ: Erlbaum.

Flavell, J. H. (1979). Metacognition and cognitive monitoring: A new area of cognitive-developmental inquiry. American Psychologist, 34, 906-911.

Flavell, J. H. (1981). Cognitive monitoring. In W. P. Dickson (Ed.), Children's oral communication skills (pp. 35-60). New York: Academic Press.

Gough, P. B. (1972). One second of reading. In J. F. Kavanaugh, \& I. C. Maltingly (Eds.), Language by ear and eye (pp. 331-358). Cambridge, MA: MIT Press.

Grabe, W. (1991). Current developments in second language reading research. TESOL Quarterly, 25(3), 375-406.

Grabe, W. (2004). Research on teaching reading. Annual Review of Applied Linguistics, 24, 44-69.

Grabe, W., \& Stoller, F. L. (2002). Teaching and researching reading. Harlow: Pearson Education.

Jacobs, J. E., \& Paris, S. G. (1987). Children's metacognition about reading: Issues in definition, measurement, and instruction. Educ. Psychol., 22, 255-278.

Johnston, P. H. (1983). Reading comprehension assessment: A cognitive basis. New Jersey: I. R. A.

Juliebö, M., Malicky, G. V., \& Norman, C. (1998). Metacognition of young readers in an early intervention programme. Journal of Research in Reading, 21, 24-35.

Koda, K. (2005). Insights into second language reading: A cross-linguistic approach. Cambridge: Cambridge University Press.

Macaro, E. (2001). Learning strategies in foreign and second language classroom. London: Continuum International.

Meneghetti, C., Carretti, B., \& De Beni, R. (2006). Components of reading comprehension and scholastic achievement. Learning and Individual Differences, 16, 291-301.

Miller, P. H. (1985). Metacognition and Attention, In Forrest-Pressley, D. L., McKinnon, E. G., \& Waller, T. G. (Eds.), Metacognition, Cognition, and Human Performance (pp. 181-221). Academic Press, New York.

Mokhtari, K., \& Reichard, C. (2002). Assessing students' metacognitive awareness of reading strategies. Journal of Educational Psychology, 94(2), 249-259.

National Institute of Child Health and Human Development. (2000). Report of the National Reading Panel. Teaching children to read: An evidence-based assessment of the scientific research literature on reading and its implications for reading instruction: Reports of the subgroups (NIH Publication No. 00-4754). C: U.S. Government Printing Office.

O’Malley, J. M., \& Chamot, A. U. (1990). Learning strategies in second language acquisition. Cambridge: Cambridge University Press.

Oxford, R. L. (1990). Language learning strategies: What every teacher should know. New York: Newbury House/Harper \& Row.

Oxford, R. L. (1994). Language learning strategies: An update. Online Resources: Digests. Retrieved November 9, 2006, from http://www.cal.org/resource/digest/oxford01.html

Paris, S., Wasik, B. A., \& Turner, J. C. (1991). The development of strategic readers. In R. Barr, M. L. Kamil, P. B. Mosenthal, \& D. Pearson (Eds.), Handbook of Reading Research (vol. 2, pp. 609-640). Mahwah, NJ: Lawrence Erlbaum.

Perfetti, C., \& Hogaboam, T. (1975). Relationship between single word decoding and reading comprehension skill. Journal of Educational Psychology, 67, 461-469.

Phakiti, A. (2003). A close look at the relationship of cognitive and metacognitive strategy use to EFL reading achievement test performance. Language Testing Journal, 20(1), 26-56.

Pressley, M. (2000). What should comprehension instruction be the instruction of? In M. L. kamli, P. B. 
Mosenthal, P. D. Pearson, \& R. Barr (Eds.), Handbook of Reading Research, 3. Lawrence Erlbaum Associates, Publishers Mahwah, New Jersey.

Pressley, M., \& Afflerbach, P. (1995). Verbal protocols of reading: The nature of constructively responsive reading. Hillsdale, NJ: Lawrence Erlbaum.

Ramesh, R. (2009). Metacognitive Strategies for Enhancing Second Language Acquisition. Manonmaniam Sundaranar University. Thirunelveli-627 012, India.

Rubin, D. B. (1987). Multiple imputations for nonresponse in surveys. New York: John Wiley \& Sons, Inc.

Rumelhart, D. E. (1977). Toward an interactive model of reading. In Dornic, S. (Ed.), Attention and Performance, 6, 573-603. New York: Academic Press.

Rumelhart, D. E. (1994). Toward an interactive model of reading. In R. Rudell, M. R. Rudell, \& H. Singer (Eds.), Theoretical models and processes of reading (4th ed.) (pp. 864-894). Newark, DA: International Reading Association.

Salataki, R., \& Akyel, A. (2002). Possible effects of strategy instruction on L1 and L2 reading. Reading in a Foreign Language, 14, 1-17.

Schraw, G. (1998). Promoting general metacognitive awareness. Instructional Science, 26(1/2), 113-125.

Sheorey, R., \& Mokhtari, K. (2001). Differences in the metacognitive awareness of reading strategies among native and non-native readers. System, 29, 431-449.

Singhal, M. (2001). Reading proficiency, reading strategies, metacognitive awareness and L2 readers. Reading Matrix, 1-9.

Slife, B. D., \& Weaver, C. A. (1992). Depression, cognitive skill, and metacognitive skill in problem solving. Cognit. Emotion, 6, 1-22.

Smith, F. (2004). Understanding reading (6th ed.). Mahwah, NJ: Lawrence Erlbaum.

Stanovich, K. (1980). Toward an interactive-compensatory model of individual differences in the development of reading fluency. Reading research Quarterly, 16, 32-71.

Swanson, H. L. (1990). Influence of metacognitive knowledge and aptitude on problem solving. J. Educ. Psychol., 82, 306-314.

Sweet, A. P., \& Snow, C. (2002). Reconceptualizing reading comprehension. In C. C. Block, L. B. Gambrell, \& M. Pressley (Eds.), Improving comprehension instruction (pp. 17-53). San Francisco, CA: Jossey-Bass.

Tang, W. N., \& Moore, D. W. (1992). Effects of cognitive and metacognitive pre-reading activities on the reading comprehension of ESL learners. Educational Psychology, 12(3/4), 315-331.

Van Duzer, C. (1999). Reading and the Adult English Language learner. ERIC Digest. ED433729.

Veenman, Van Hout-Wolters, B., H. A. M., \& Afflerbach, P. (2006). Metacognition and learning: Conceptual and methodological considerations. Metacognition Learning, 1, 3-14.

Veenman, M. V. J. (2005). The assessment of metacognitive skills: What can be learned from multimethod designs? In C. Artelt, \& B. Moschner (Eds), Lernstrategien und Metakognition: Implikationen fur Forschung und Praxis (pp. 75-97). Berlin: Waxmann.

Veenman, M. V. J., Kok, R., \& Blöte, A. W. (2005). The relation between intellectual and metacognitive skills in early adolescence. Instructional Science, 33, 193-211.

Wang, J., Spencer, K., Minjie, \& Xing, M. (2009). Metacognitive beliefs and strategies in learning Chinese as a foreign language. System, 37(1), 46-56.

Zare-ee, A. (2008). The relationship between cognitive and meta-cognitive strategy use and EFL reading achievements. Faculty of Foreign Language and Literatue, IslamicAzad University, Roudehen Branch, Tehran, Iran. The first regional conference on English language teaching and literature (ELTL-1).

\section{Copyrights}

Copyright for this article is retained by the author(s), with first publication rights granted to the journal.

This is an open-access article distributed under the terms and conditions of the Creative Commons Attribution license (http://creativecommons.org/licenses/by/3.0/). 